\title{
Research article \\ In vitro antioxidant and antifungal activity of methanol root extract of Flacourtia indica (Burm.f.) Merr. against selected fungal species
}

\author{
Eramma N., Gayathri Devaraja \\ Department of Microbiology, Davangere University, Shivagangothri, Davangere 577007, Karnataka, India
}

(Received: June 2021

Revised: July 2021

Accepted: July 2021)

Corresponding author: Gayathri Devaraja. E-mail: gayathridevaraja@gmail.com

\begin{abstract}
Introduction and Aim: Flacourtia indica (Burm.f.) Merr. is a member of the family Flacourtiaceae. This herb was used to treat a range of ailments and served as the foundation for ethnomedicine. Despite its enormous medical importance, the plant has received very little research with only a few antibacterial and pharmacological studies. The plant's roots, in particular, are understudied. In this study, the antioxidant and antifungal activities of methanol $(\mathrm{MeOH})$ root extract of $F$. indica was tested in vitro.

Materials and Methods: Antifungal activity was assessed against human fungal pathogens, Aspergillus niger (MTCC 404) and Trichophyton mentagrophytes (MTCC 7687). The natural antioxidants in roots were studied using five different antioxidant methods, including 2, 2-diphenyl-1-picrylhydrazyl (DPPH), nitric oxide scavenging (NOS), reducing power assay (RPA), measuring total phenolic content (TPC) by Folin-Ciocalteu Reagent (FCR).

Results: When compared to Aspergillus niger, the root extract has strong antifungal activity against Trichophyton mentagrophytes (MTCC 7687), generating a broader zone of inhibition (MTCC 404). Clotrimazole is a common antifungal medicine that can be used as a positive control in this investigation. The antioxidant activity of $\mathrm{MeOH}$ root extract increased in a dose-dependent manner, and it had outstanding NOS and antioxidant properties.
\end{abstract}

Conclusion: The results conclude that, $F$. indica appears to be a promising herbal option for the treatment of a variety of fungal and bacterial infections, with high antioxidant capacity.

Keywords: Antifungal activity, Antioxidant property, DPPH, Total flavonoids, Reducing power assay.

\section{INTRODUCTION}

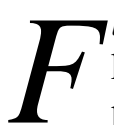
lacourtia indica (Burm.f.) Merr., sometimes known as " Tuturi or 'Baichi' or 'Katai' or Indian plum," is a beneficial medicinal plant. It is widely distributed throughout the Himalayas, northern districts of Uttar Pradesh, Assam, Bengal and Orissa, Bangladesh and India (1). Previously, the genus $F$. indica was named after Étienne de Flacourt (16071660), a governor of Madagascar, and was placed in the Flacourtiaceae family (2). A lot of studies have found that the entire plant contains bioactive components such as antibacterial, antifungal, antioxidant, anti-proliferative, hepatoprotective and anti-asthmatic activity [3-9], A phytochemical investigation of $F$. indica revealed the presence of alkaloids, tannins, saponins, flavonoids, glycosides, phenolic compounds, terpenoids, and steroids (3).

Medicinal plants have been shown to be an excellent source of bioactive chemicals. The primary function of these chemicals is to protect plants from phytopathogenic agents and destructive insects carried by herbivorous animals. These plants produce antibacterial secondary metabolites; therefore, screening medicinal plants provides another option for developing antimicrobials. There are a few kinds of antifungal medications that can be used to treat a variety of fungal illnesses in humans, animals, and plants. However, with an alarming growth in the global prevalence of infectious fungal illnesses arising and re-emerging, as well as the development of resistance to currently existing antifungal treatments, there is an urgent need for alternative sources of antifungal drugs derived from medicinal plants is major concern (10).

The human body continually generates harmful free radicals. Normally, free radicals are chemically reactive because they contain oxygen and these species are called reactive oxygen species (ROS). Some of the reactive oxygen species (ROS) formed in vivo includes superoxide radicals, hydroxyl radicals, singlet oxygen and hydrogen peroxide are the byproducts generated during metabolic reactions (5). They can attack lipids of the cell membranes, inducing oxidations that cause membrane lipid peroxidation which decreases the membrane fluidity and reactive oxygen species also attack genetic material, DNA causing mutation and which may end up with cancer, hypertension, obesity, inflammation, diabetes, ageing, immunosuppression and neurodegenerative disorders, etc., $(2,11)$.

Phytoconstituents like alkaloids, flavonoids, phenolic compounds, terpenes, vitamin $\mathrm{C}$, vitamin $\mathrm{E}, \alpha-$ carotene, selenium, polyphenols, glutathione, peroxidase and cysteine are potent antioxidants which can acts as very good supplements to the humans through diet (11). This may ensure the best protection against the development of diseases due to oxidative stress caused by free radicals (12). Natural 
antioxidants inhibit the process of oxidation even at very low concentration and have a diverse physiological role in the body (13). Regular consumption of anti-oxidative vegetables and fruits reduces the risk of chronic diseases. As a result, there is an increasing trend in the use of medicinal plants for remedies, with the process of extraction, isolation, innovation of newer drugs, and their use as pharmacotherapeutics from selected plants being identified as an industrial output. The vast therapeutic potential of $F$. indica may open an alternative door to the pharma industry (14).

Therefore, methods of isolation, purification, and characterization of bioactive principles are most important for understanding the mechanism of action of antimicrobial and antioxidant properties both in vivo and in vitro. Moreover, isolation of active principles largely depends on the solvents being used for the extraction process. Development of antifungal biomolecules with diverse chemical structures and novel mechanisms of action is necessary. The investigations into new antifungal substances should be continued and all possible strategies and techniques need to be explored further. In this context, the antifungal and antioxidant activity of $\mathrm{MeOH}$ root extract of $F$. indica is reported.

\section{MATERIALS AND METHODS}

\section{Plant material}

The plant and its roots were taken in a natural habitat near Udupi, Karnataka, at latitude $13^{\circ} .33^{\prime} N$. On the basis of typical features, the plant was taxonomically identified and authenticated by Sri V. Aravinda Hebbar, Retd. Associate Professor of Botany, Udupi district, Karnataka, India. The roots were washed several times with running water, and then distilled water, shade dried, pulverized, and stored in an airtight container until needed.

\section{Preparation of plant extract}

A hot extraction technique utilizing a Soxhlet extractor was used to extract methanol from $100 \mathrm{gm}$ of air-dried root powder of $F$. indica for 72 hours. The root extract is then distilled in methanol and condensed under vacuum to recover it. The resultant semisolid mass was vacuum dried using a rotary flash evaporator to yield solid residue. The solvent extract was weighed and stored in an airtight container at 4 ${ }^{\circ} \mathrm{C}$. phytochemical analyses, as well as antifungal and antioxidant tests, are performed on the extracted materials (5).

\section{Antifungal activity of $\mathrm{MeOH}$ root extract}

\section{Fungal cultures used for the study}

Two fungal pathogens, Aspergillus niger (MTCC 404) and Trichophyton mentagrophytes (MTCC 7687) were procured from MTCC (IMTeCH, Chandigarh,
India) used for in vitro antifungal activity by agar well diffusion assay (15).

\section{Chemicals and reagents}

Potato Dextrose Agar (PDA) media and standard antibiotic clotrimazole $(30 \mu \mathrm{g} / \mathrm{ml})$ were used for antifungal activity. Various chemicals used for antioxidant activity include ascorbic acid, gallic acid, quercetin, sodium hydroxide, aluminum chloride, sodium nitrite, potassium ferricyanide, trichloroacetic acid, sodium carbonate, ferric chloride and acetic acid, Folin-Ciocalteu's reagent and free radical 1, 1Diphenyl-2-pycrylhdydrazyl (DPPH) were obtained from Sigma-Aldrich Pharmaceuticals Ltd, Bangalore, and Karnataka, India.

\section{Agar well diffusion assay}

The agar well diffusion method was used to test antifungal activity. In a sterile petri plate, around 25 $\mathrm{mL}$ of molten potato dextrose agar was poured (Himedia, Mumbai, India). After the plates had solidified, a three-day-old fungal suspension $(105 \mathrm{cfu} / \mathrm{ml}, 100 \mathrm{l})$ was swabbed with a sterile swab. The test samples were placed into wells with different concentrations of $25 \mu \mathrm{g} / \mathrm{ml}, 50 \mu \mathrm{g} / \mathrm{ml}, 100 \mu \mathrm{g} / \mathrm{ml}$, and $200 \mu \mathrm{g} / \mathrm{ml}$. Clotrimazole $(30 \mu \mathrm{g} / \mathrm{ml})$ was added as a conventional antifungal agent. The experiment was carried out in triplicates. All of the loaded plates were maintained for 48 to 72 hours. The diameter of the zone of inhibition around the well was measured using the antibiotic zone to determine antifungal activity (15).

\section{Determination of In-vitro antioxidant activity of $\mathrm{MeOH}$ root extract}

\section{Preparation of test sample and standard solutions}

The methanol root extract of $F$. indica and the standard antioxidants like ascorbic acid and quercetin were prepared separately by dissolving in Dimethyl Sulphoxide (DMSO). These standards were used for in-vitro antioxidant assay. Stock solutions were serially diluted with DMSO to get required dilutions (16).

\section{DPPH free radical scavenging assay}

The antioxidant activity of the methanol extract of root and standard components was determined using the radical scavenging action of the stable DPPH free radical. With minor modifications, its antioxidant activity was measured (17). The DPPH solution was prepared by dissolving $0.004 \%$ of DPPH in methanol and the remaining volume was made up to $100 \mathrm{ml}$ of methanol. Then different concentrations of $10,30,50$, $70,90,100 \mu \mathrm{g} / \mathrm{ml}$ of methanol root extract of the plant were prepared. After 30 minutes in the dark, $3 \mathrm{ml}$ of DPPH solution was added to each concentration and absorbance was measured at $517 \mathrm{~nm}$ spectrophotometrically (Systronics, India) against the corresponding test blank. Low absorbance reaction 
mixture indicates higher free radical scavenging activity. Ascorbic acid can be used as standard by preparing similar concentrations $(10,30,50,70,90$, $100 \mu \mathrm{g} / \mathrm{ml}$ ) in this study. All tests were run in triplicates and mean values were taken for calculation by using the following equation (18).

\section{$\%$ inhibition $=\left(\mathbf{A}_{0}-\mathbf{A}_{1}\right) / \mathbf{A}_{0} \mathbf{X 1 0 0}$}

Where, $\mathrm{A}_{0}$ was the absorbance of control (without extract) and $A_{1}$ was the absorbance in the presence of extract.

\section{Reducing power assay}

The Fe3+ reducing power of the crude root extract at different fractions was evaluated using the Oyaizu method (18). 6 various strengths of root extract in $\mathrm{mL}$ $20,40,60,80$, and $100 \mathrm{~g} / \mathrm{ml}$ were combined with 2.5 $\mathrm{ml}$ of phosphate buffer $(0.2 \mathrm{M}, \mathrm{pH} 6.6)$ and $2.5 \mathrm{ml}$ of potassium ferricyanide $(1 \%)$, after that mixture is incubated at $50{ }^{\circ} \mathrm{C}$ for 20 minutes. To the reaction mixture, $2.5 \mathrm{ml}$ of trichloro-acetic acid10\% was added. It was centrifuged at $1500 \mathrm{rpm}$ for 10 minutes, then $2.5 \mathrm{ml}$ of the supernatant was mixed uniformly with $0.5 \mathrm{ml}$ of ferric chloride (1\%), and the absorbance was measured spectrophotometrically at $700 \mathrm{~nm}$. Increased absorbance of the reaction mixture indicated increased reducing power. Gallic acid can be used as a positive control. The results were expressed in milligram equivalents of Gallic acid per milligram of dry weight. The calibration line was established using the following concentrations of Gallic acid: 5, 10, 20, 30 , and $50 \mu \mathrm{g} / \mathrm{ml}$.

\section{Nitric oxide scavenging (NOS) assay}

The Nitric oxide scavenging assay was determined according to the method described by Garrot (20) with slight modifications. At physiological $\mathrm{pH}$, sodium nitroprusside rapidly generates nitric oxide, which intern reacts with oxygen to produce nitric ions, as determined by the Griess Illosvoy reaction. $2 \mathrm{ml}$ of $5 \mathrm{mM}$ sodium nitroprusside in $0.5 \mathrm{ml}$ phosphate buffer saline (pH 7.4) was mixed with $0.5 \mathrm{ml}$ of root extract at different concentrations $(10,50,100,150,200$ $\mu \mathrm{g} / \mathrm{ml})$. The mixture was then incubated at $25^{\circ} \mathrm{C}$ for $150 \mathrm{~min} .0 .5 \mathrm{ml}$ was taken out from the incubated mixture and $1 \mathrm{ml}$ of sulphanilic acid reagent $(0.33 \%$ in $20 \%$ glacial acetic acid or Griess reagent) was added then incubated again at room temperature for $30 \mathrm{~min}$. The absorbance was then measured at $540 \mathrm{~nm}$ spectrophotometrically. The nitric oxide radical scavenging activity was then calculated by the following formula (5).

\section{Percentage $(\%)$ of inhibition $=\left[\left(A_{0}-A_{1}\right) / A_{0} X 100\right]$}

Where $\mathrm{A}_{0}$ was the absorbance of the control (blank, without extract) and $A_{1}$ was the absorbance in the presence of the extract/standard.

\section{Total flavonoid content (TFC) assay}

The total flavonoid content of the methanol root extract was estimated by the aluminum chloride colorimetric method. Total flavonoid content of the root extract was determined by referring a method described previously by Tyagi et al., (5) with slight modifications. In brief, $1 \mathrm{ml}$ of methanol root extract $(100 \mu \mathrm{g} / \mathrm{ml})$ and $2 \mathrm{ml}$ of water was taken in a $10 \mathrm{ml}$ standard flask. After 5 minutes, $3 \mathrm{ml}$ of $5 \%$ sodium nitrite and $0.3 \mathrm{ml}$ of $10 \%$ aluminum chloride were added. After $6 \mathrm{~min}, 2 \mathrm{ml}$ of $1 \mathrm{M}$ sodium hydroxide was added and the volume made up to $10 \mathrm{ml}$ with water. The absorbance of the reaction mixture was measured $(510 \mathrm{~nm})$. Quercetin can be used as a standard to construct a standard curve and flavonoid content is expressed as quercetin equivalent in $\% \mathrm{w} / \mathrm{w}$ of the extract [2]. All experiments were carried out in triplicate. Total flavonoid content was calculated as $\mathrm{mg} \mathrm{QE} / \mathrm{g}$, using the following equation based on the calibration curve:

$$
Y=0.0008 x+0.0124, R^{2}=0.9683 .
$$

Where $\mathrm{x}$ was the absorbance and $\mathrm{y}$ was the $\mathrm{mg} \mathrm{QE} / \mathrm{g}$.

\section{Total phenolic content (TPC) assay}

The Folin-Ciocalteu method was used to assess the total phenolic content of the methanol root extract of F. indica $(21,22) .1 \mathrm{ml}$ Folin-Ciocalteu reagent was combined with $0.02 \mathrm{mg} / \mathrm{ml}(20 \mathrm{~g} / \mathrm{ml})$ root extract in 25 $\mathrm{ml}$ volumetric flask and $2 \mathrm{ml}$ of $2 \%$ sodium carbonate added to it and mixed well then kept incubation for 2 hr. After incubation, development of blue color was measured $(760 \mathrm{~nm})$. The standard curve was prepared by using Gallic acid standard and linearity was obtained in the range of 4 to $25 \mu \mathrm{g} / \mathrm{ml}$. All experiments were carried out in triplicate. Total phenolic content was expressed in mg GAE per gram of extracts, using a calibration curve. $\mathrm{Y}=0.0542 \mathrm{x}+0.1087, \mathrm{R}^{2}=0.9734$

\section{Statistical Analysis}

All the methods were carried out in triplicates. Results were expressed as mean value $\pm \mathrm{SD}(\mathrm{n}=3)$. The statistical significance for the biological activity was evaluated using an ANOVA, p-values less than 0.05. Regression analysis was performed to calculate the dose response relation between the extracts and standards.

\section{RESULTS}

\section{Antifungal activity of $\mathrm{MeOH}$ root extract}

$F$. indica $\mathrm{MeOH}$ root extract inhibited the tested fungi. The plant root extract at the concentrations of 25, 50, $100,200 \mathrm{mg} / \mathrm{ml}$ showed lower activity (narrow zone) against Aspergillus niger compared to Trichophyton mentagrophyte. Root extract was found to be potential against $T$. mentagrophyte forming a wider inhibition zone of $12 \pm 00$ at the concentration of $200 \mathrm{mg} / \mathrm{ml}$ and against $A$. niger forming a narrow zone of inhibition of $8 \pm 00$ at the same concentration when compared to clotrimazole standard as shown in the (Fig 1A and B). The results of the antifungal spectrum of the extract are represented in Table 1. 

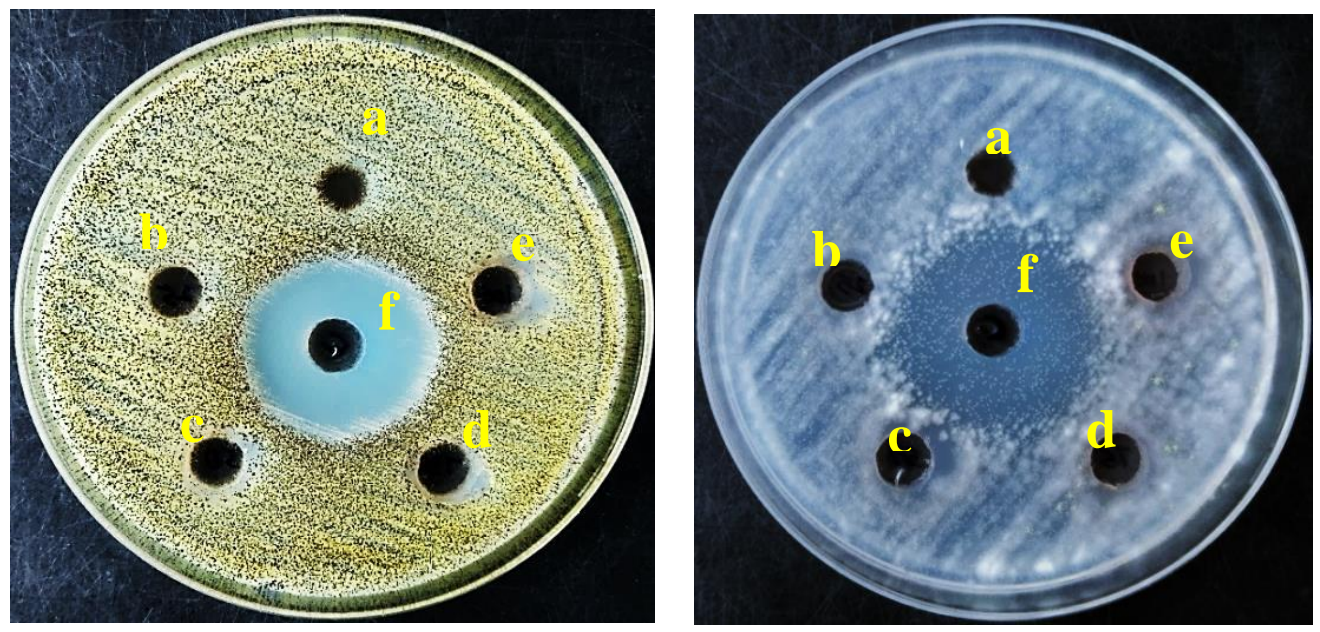

Fig.1: Antifungal activity of root extract against A. niger and T. mentagrophytes. A) Aspergillus niger B) Trichophyton mentagrophytes; a: $0 \mathrm{mg} / \mathrm{ml}$; b: $25 \mathrm{mg} / \mathrm{ml}$; $: 50 \mathrm{mg} / \mathrm{ml}$; $: 100 \mathrm{mg} / \mathrm{ml}$; e: $200 \mathrm{mg} / \mathrm{ml}$; f: Clotrimazole $(30 \mu \mathrm{g} / \mathrm{ml})$

Table 1: Zone of inhibition of the root extracts against Aspergillus niger and Trichophyton mentagrophytes

\begin{tabular}{|c|c|c|c|c|c|}
\hline Organisms & \multicolumn{5}{|c|}{ Diameter of Zone of inhibition $(\mathrm{mm})$} \\
\hline Concentration & $25 \mathrm{mg} / \mathrm{ml}$ & $50 \mathrm{mg} / \mathrm{ml}$ & $100 \mathrm{mg} / \mathrm{ml}$ & $200 \mathrm{mg} / \mathrm{ml}$ & $30 \mu \mathrm{g} / \mathrm{ml}^{*}$ \\
\hline Aspergillus niger & ND & $7 \pm 00$ & $7 \pm 00$ & $8 \pm 00$ & $22 \pm 00$ \\
\hline Trichophyton mentagrophytes & $8 \pm 00$ & $9 \pm 00$ & $10 \pm 00$ & $12 \pm 00$ & $24 \pm 00$ \\
\hline
\end{tabular}

The values are mean inhibition zone $(\mathrm{mm})(\mathrm{n}=3) \pm$ SD. ND =not detected, $*$ Clotrimazole

\section{DPPH free radical scavenging activity}

The antioxidant activity of crude methanol $(\mathrm{MeOH})$ root extract of $F$. indica was comparable to that of standard ascorbic acid at various doses (Table 2). According to the findings, all concentrations tested showed a dose-dependent increase in antioxidant activity and a decrease in absorbance. More than $92 \%$ of DPPH radical scavenging activity was detected at a concentration of $100 \mu \mathrm{g} / \mathrm{ml}$, with an $\mathrm{IC}_{50}$ value of $42.73 \mu \mathrm{g} / \mathrm{ml}$. The ascorbic acid standard demonstrated strong DPPH radical inhibition with an $\mathrm{IC}_{50}$ value of $44.52 \mu \mathrm{g} / \mathrm{ml}$ and $91 \%$ inhibition under the same experimental conditions.

Table 2: DPPH radical scavenging activity of methanol root extract of $F$. indica and ascorbic acid

\begin{tabular}{|c|c|c|c|}
\hline $\begin{array}{c}\text { Root Extract } \\
\text { Concentration }(\boldsymbol{\mu g} / \mathbf{m l})\end{array}$ & \% Inhibition & $\begin{array}{c}\text { Ascorbic acid } \\
\text { Concentration }(\boldsymbol{\mu g} / \mathbf{m l})\end{array}$ & \% Inhibition \\
\hline Control & 100 & Control & 100 \\
\hline 10 & $76.10 \pm 0.17$ & 10 & $61.82 \pm 1.5$ \\
\hline 30 & $84.03 \pm 0.05$ & 30 & $68.69 \pm 0.9$ \\
\hline 50 & $84.57 \pm 0.15$ & 50 & $77.48 \pm 0.03$ \\
\hline 70 & $87.10 \pm 0.17$ & 70 & $84.05 \pm 0.04$ \\
\hline 90 & $91.28 \pm 0.07$ & 90 & $91.32 \pm 0.38$ \\
\hline 100 & $92.06 \pm 0.1$ & 100 & $91.21 \pm 0.01$ \\
\hline IC50 & $\mathbf{4 2 . 7 3}$ & IC $50_{\mathbf{5 0}}$ & $\mathbf{4 4 . 5 2}$ \\
\hline
\end{tabular}

Scavenging ability are mean values of three determinants $(n=3) \pm$ SD

\section{Reducing power activity}

The results of the $\mathrm{MeOH}$ root extract revealed a potent reducing power activity that increased with the increasing concentration of the sample. The reduction ability i.e., transformation of $" \mathrm{Fe}^{3+}$ to $\mathrm{Fe}^{2+"}$ results in the increasing absorbance with rising concentration.
This was compared with the Gallic acid standard (Table.3). The flavonoids and phenolic acids are present in the root extract exhibit strong reduction capacities. The reduction capacity of $\mathrm{MeOH}$ root extract of $F$. indica and Gallic acid is reported (Fig.2, $3)$.

Table 3: Reducing power activity of methanol root extract and gallic acid standard

\begin{tabular}{|c|c|c|c|}
\hline $\begin{array}{c}\text { Root Extract } \\
\text { Concentration }(\boldsymbol{\mu g} / \mathbf{m l})\end{array}$ & $\mathbf{A}_{\mathbf{7 0 0} \mathbf{n m}}$ & $\begin{array}{c}\text { Gallic Acid } \\
\text { Concentration }(\boldsymbol{\mu g} / \mathbf{m l})\end{array}$ & $\mathbf{A}_{\mathbf{7 0 0 n m}}$ \\
\hline 20 & $0.049 \pm 0.05$ & 5 & $0.075 \pm 0.0$ \\
\hline 40 & $0.084 \pm 0.05$ & 10 & $0.161 \pm 0.0$ \\
\hline 60 & $0.118 \pm 0.046$ & 20 & $0.471 \pm 0.0$ \\
\hline 80 & $0.153 \pm 0.10$ & 30 & $0.811 \pm 0.0$ \\
\hline 100 & $0.363 \pm 0.27$ & 50 & $1.220 \pm 0.0$ \\
\hline
\end{tabular}

Values are mean of triplicate determination $(n=3) \pm S D$ 


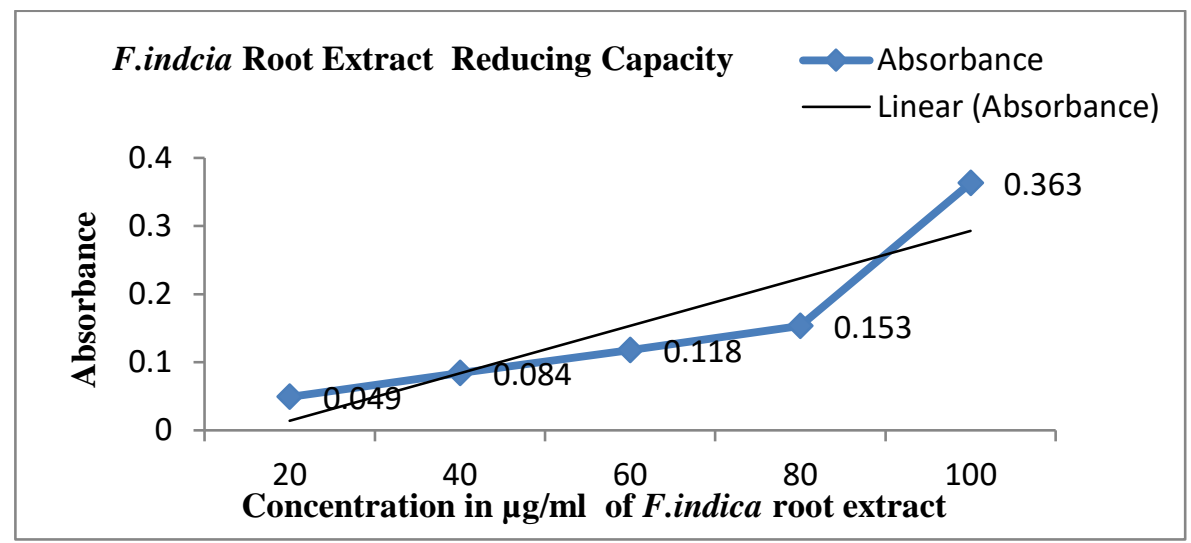

Fig. 2: Reducing power assay of $\mathrm{MeOH}$ root extract of $F$. indica. Values are mean of triplicate determination $(\mathrm{n}=3) \pm \mathrm{SD}$

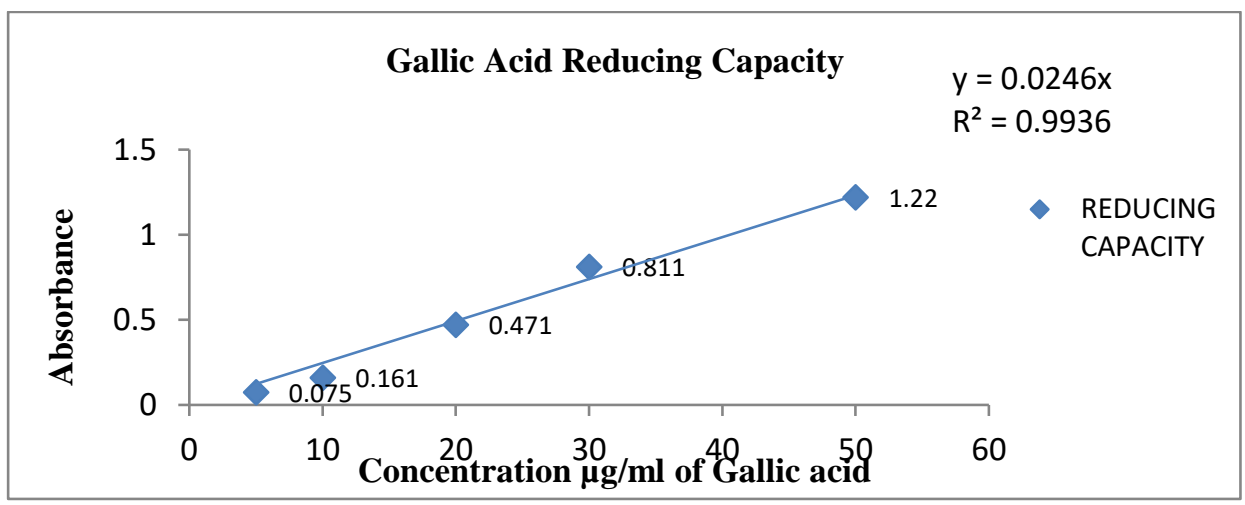

Fig. 3: Reducing power assay of gallic acid. Values are mean of triplicate determination $(n=3) \pm S D$

Nitric oxide scavenging (NOS) activity

Under in vitro circumstances, a dose-dependent increase in nitric oxide scavenging activity was reported. At a concentration of $200 \mu \mathrm{g} / \mathrm{ml}$, both root extracts and ascorbic acid standard show promising nitric oxide scavenging activity, inhibiting NOS by more than $57 \%$ and $91 \%$, respectively, with $\mathrm{IC}_{50}$ values of $172.41 \mu \mathrm{g} / \mathrm{ml}$ and $95.56 \mu \mathrm{g} / \mathrm{ml}$ (Table.4).

Table 4: Nitric oxide scavenging activity of methanol root extract of $F$. indica and ascorbic acid standard

\begin{tabular}{|c|c|c|c|}
\hline $\begin{array}{c}\text { Root extract } \\
\text { Concentration }(\boldsymbol{\mu g} / \mathbf{m l})\end{array}$ & \% Inhibition & $\begin{array}{c}\text { Ascorbic acid } \\
\text { Concentration }(\boldsymbol{\mu g} / \mathbf{m l})\end{array}$ & \% Inhibition \\
\hline 10 & $12 \pm 0.30$ & 10 & $22.8 \pm 0.01$ \\
\hline 50 & $15.2 \pm 2.1$ & 50 & $55.43 \pm 00$ \\
\hline 100 & $35.08 \pm 0.1$ & 100 & $67.33 \pm 0.04$ \\
\hline 150 & $42.2 \pm 00$ & 150 & $73.9 \pm 0.005$ \\
\hline 200 & $57.16 \pm 0.05$ & 200 & $91.83 \pm 0.005$ \\
\hline IC 50 & $\mathbf{1 7 2 . 4 1 \pm 0}$ & IC $\mathbf{5 0}_{\mathbf{5 0}}$ & $\mathbf{9 5 . 9 6} \pm \mathbf{0}$ \\
\hline
\end{tabular}

Scavenging ability are mean values of three determinants $(n=3) \pm$ SD

\section{Total flavonoid content activity}

The total flavonoid content of $\mathrm{MeOH}$ root extract of $F$. indica was determined to be $92.3 \mathrm{mg}$ of quercetin equivalent/g of root extract, with a significant $\mathrm{R}^{2}$ value of 0.9683 (Fig. 4), as determined by the quercetin calibration curve regression equation.

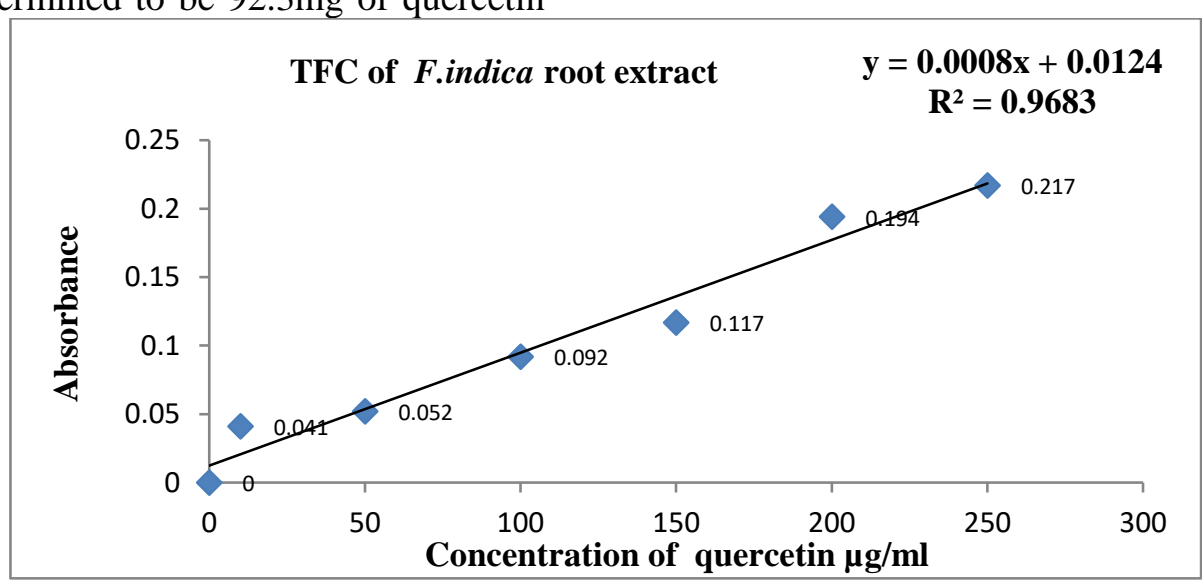

Fig. 4: Total flavonoid content estimation using Quercetin standard curve. Values are mean of triplicate determination $(\mathrm{n}=3) \pm$ 


\section{Total phenolic content activity}

The total phenol content of $\mathrm{MeOH}$ root extracts was measured as Gallic acid equivalents per gram of dry extract and found to be $18.6 \mathrm{mg} \mathrm{GA} / \mathrm{g}$ using a linear regression equation of Gallic acid standard with an $\mathrm{R}^{2}$ value 0.934 (Fig.5).

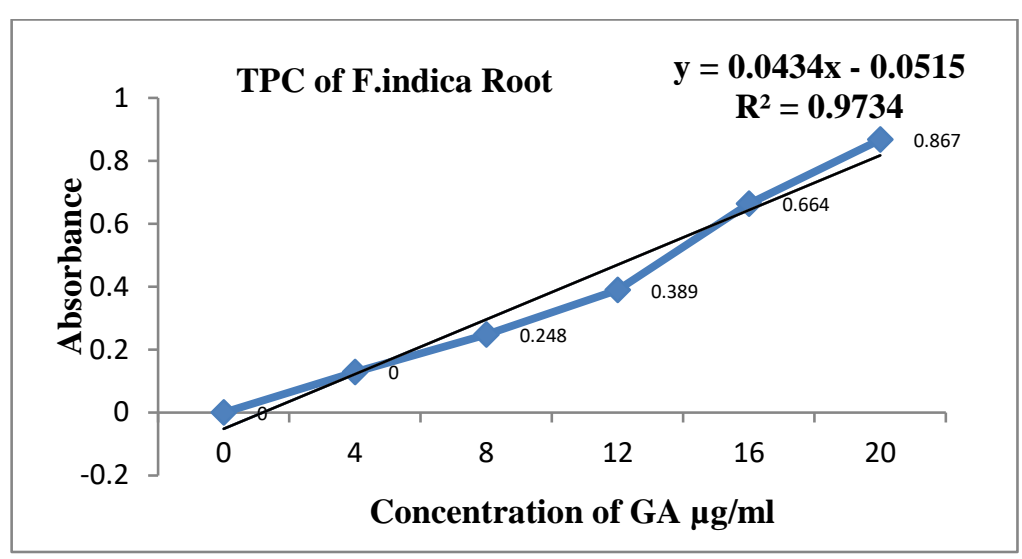

Fig. 5: Total phenolic content estimation using Gallic acid standard curve. Values are mean of triplicate determination $(\mathrm{n}=3) \pm$ SD

\section{DISCUSSION}

The existence of numerous bioactive phytochemicals employed against various illnesses is attributed to the healing capabilities of medicinal plants $(2,22)$. Antifungal and antioxidant results demonstrated that the $F$. indica root extract has substantial antifungal and radical scavenging effects in the current investigation. Aerial components of this plant extract have been shown to have substantial antibacterial and antifungal properties in numerous investigations. Our antifungal results were comparable to those reported in prior studies (4). The results of A. niger demonstrated a clear connection, with no activity at lower concentrations $(25 \mathrm{mg} / \mathrm{ml}$ and $50 \mathrm{mg} / \mathrm{ml})$ but modest antifungal action at higher doses (100 and $200 \mathrm{mg} / \mathrm{ml})$. These data suggest that higher doses of plant extracts would be more effective against the fungal diseases investigated.

The $\mathrm{MeOH}$ root extract of $F$. indica has significant radical scavenging action, as evidenced by the DPPH experiment. Previous research has also suggested that aerial parts of F.indica have dose-dependent radical scavenging activity (5). However, in the current work, we discovered that the plant's roots extract inhibited radicals more than the aerial parts. This could be owing to significant changes in nature and kind, as well as antioxidant distribution in different sections of the plant (23).

The presence of certain reductants is generally associated with the reducing characteristics (24). The reducing capability of an $F$. indica root extract found in this study could be a useful predictor of its potential antioxidant activity. It can be detected by a rise in the absorbance of the reaction mixture as the reducing power rises. Reductants have an antioxidant effect by breaking the free radical chain by donating a hydrogen atom (25). The antioxidant activity of phenolic compounds is mostly owing to their redox characteristics, which can aid in the absorption and neutralization of free radicals, as well as the quenching and decomposition of singlet and triplet oxygen and peroxides (26). Flavonoids, like phenols, are significant plant components because of their active hydroxyl groups and antioxidant properties (27). From the current research, it is understood that, the methanol root extract of F. indica showed an encouraging response in quenching nitric oxide radicals when compared to ascorbic acid. Our observation is in agreement with the studies of Tyagi et al., (5). The presence of active principles such as flavonoids and phenolic compounds in $\mathrm{MeOH}$ extracts of roots was also shown to be positively correlated, suggesting that they may be responsible for the considerable antibacterial and radical scavenging action. Flavonoids are potent antioxidants with major biological functions such as quenching of oxygen free radicals, inhibition of lipid peroxidation, and so on (24). Flavonoids have long been known to have antioxidant properties, and their impact on human nutrition and health is significant. Flavonoids work by scavenging or chelating the free radicals in the body. Phenolic substances, a family of antioxidant metabolites, can act as free radical terminators in the biological system (27). Various authors estimated and reported the flavonoid content of $F$. indica using the aluminium chloride technique. The presence of flavanones and flavones, as well as their pharmacological effectiveness, has been investigated in $F$. indica leaf extract (27). Because there is no previous evidence of $F$. indica root extract's antimicrobial and antioxidant property in the literature was found. This work could be used as a model.

\section{CONCLUSION}

From this study, it may be concluded that the $\mathrm{MeOH}$ root extract $F$. indica showed significant antifungal and potential antioxidant activities. This is the first report that we are aware of that demonstrates significant antioxidant activity due to the presence of significant amounts of flavonoids and phenolic compounds in the roots, which are identical to the 
aerial parts. The assessment of antioxidant properties can be used as a reference for using these plants in the prevention of cardiovascular and other oxidative stress-related diseases, and thus they are of great interest in human health. These findings support the use of $F$. indica roots in traditional medicine, particularly in the treatment of nephritic colic and psychopathy. The entire plant can also be used to treat skin diseases, pruritus, erysipelas, snake bites, arthritis, and other disorders. Therefore, $F$. indica perhaps be promoted as an herbal candidate for the treatment of various diseases and related complications in modern medicines after suitable validation. More research is needed to completely understand the phytochemicals responsible for this effect, so that the isolation and identification of responsible bioactive components can aid in the study of their mechanisms of action, which will aid in the development of future herbal drug formulations.

\section{CONFLICT OF INTEREST}

The author declare no conflict of interest

\section{REFERENCES}

1. Swati, M., Gyanendra Nath, S., Yatendra, K., Kanchan, K., Raman Mohan, S., Om Prakash. Phytochemical analysis and free-radical scavenging activity of Flacourtia indica (Burm.f.) Merr. J. Pharm. Res. 2009; 8(2): 81-84.

2. Sasi, S., Anjum, N., Tripathi, Y. C. Ethnomedicinal, phytochemical and pharmacological aspects of Flacourtia jangomas: a review. Int. J. of Pharmc and Pharm Sci. 2018; 10(3): ISSN- 0975-1491.

3. Eramma, N., Devaraja, G. Antibacterial potential and phytochemical analysis of Flacourtia indica (Burm.f.) Merr. root extract against human pathogens. Indo Am. J. Pharm Res. 2013; 3(5): 3832-3846.

4. Hajra, S., Mehta, A., Pandey, P. Assessment of antimicrobial activity of Cassia fistula and Flacoartia indica leaves. J. of Pharmac. Res. 2011; 4(7): 2432-2435.

5. Tyagi, S. N., Rakshit, M., Gyanendra Nath, S., Yatendra, K., Kanchan, K., Raman Mohan, S., Om Prakash. Phytochemical analysis and free-radical scavenging activity of Flacourtia indica (Burm.f.) Merr. J of Pharma Res. 2009 April; 8 (2): 81-84.

6. Musewu, C. J., Mapanga, R. F. In vitro evaluation of fruit extracts of Annona stenophylla diels and Flacourtia indica for incorporation into formulations for management of cancer. J of Med Plan Res. 2019; 13(11): 242-251.

7. Varkey, J., Thomas, J. Protective effect of Flacourtia indica (Burm.f) Merr. in methotrexate induced hepatotoxicity. Pharma Nest. 2011; 2(2-3): 115-123.

8. Nazneen, M., Mazid, M. A., Kundu, J. K., Bachar, S. C., Rashid, M. A., Datta, B. K. Phytochemical and biological studies of $F$. indica, Dhaka Univ J Biol Sci. 2002; 11(2): 183-187.

9. Gnanaprakash, K., Chetty, C. M., Ramkanth, S., Alagusundaram, M., Tiruvengadarajan, V. S., Parameswari, S. A., et al., Aqueous Extract of Flacourtia indica prevents carbon tetrachloride induced hepatotoxicity in rat. Int J Biol Life Sci. 2010; 6(1): 51-55.

10. Mahlo, S. M., Chauke, H. R., McGaw, L. Antioxidant and antifungal activity of selected medicinal plant extract against phytopathogenic fungi. Afr J Tradit Complement Altern Med. 2016; 13(4): 216-222.

11. Asma`a Al-Rifai, Ahmad Aqel, Tarfah Al-Wahi, Saikh M.Wabaidur, Zeid A. Al-Othman and A. Yacine BadjahHadji-Ahmed. Antibacterial, antioxidant activity of ethanolic plant extracts of some Convolvulus species and their DART-ToF-MS Profiling. Evi-Bas Compl and Alter Medi. 2017; Article ID 5694305, Pp 9.

12. Mathur, R., Vijayvergia, R. Determination of total flavonoid and phenol content in Mimusops elengi linn. Int. J. of Phar. Sci. Rea. 2017; 8(12): 5282-5285.

13. Vitalis, I., Francis, I. Antioxidant Activities of Aqueous and Methanol Extracts of Flacourtia indica Fruit (Governor's Plum) on Cadmium induced Toxicity in Albino Wistar Rats. Int J of Sci and Adv Innov Res. 2019 4(4): Dec, ISSN: 2536-7315 (Print) 2536-7323 (Online).

14. Chatterjee, M., Chandra, I., Chatterjee, S. I. Flacourtia indicia (Burm. f.) Merr. - An Ethnopharmacologicaly valuable plant, review article. In. J. of Herb Med. 2015; 2 (1): $26-27$.

15. Magaldi, S. Mata-Essayag, S., Hartung de Capriles, C., Perez, C., Colella. M. T. Carolina Olaizola and Yudith Ontiveros. Well diffusion for antifungal susceptibility testing. Int. J of Infect Dis. 2004; 8 (1): 39-45.

16. Lalsare, S., Verma, K. P., Khatak, M., Ranjan, S., Rajurakar, S., Gurav, S. S. Anti-inflammatory and Antimicrobial activity of Flacourtia ramontchi leaves. Int J Drug Dev and Res. 2011; 3(2): 308-313.

17. Himaja, M., Ranjitha, A., Ramana, M. V., Anand, M and Asif, K. Phytochemical screening and antioxidant activity of rhizome part of Curcuma zedoaria. Int. J. of Res. in Ayur \& Pharmacy. 2010; 1(2): 414-417.

18. Oyaizu, M. Studies on product of browning reaction prepared from glucose amine. Jap. J. Nutr. 1986; 44. [Google Scholar]

19. Garrat, D.C. The quantitative analysis of drugs. Chapman and Hal Ltd, Japan. 1964: 456.

20. Slinkard, K and Singleton, V. L. Total phenol analysis: automation and comparison with manual methods. Am. J. Enol. Vitic. 1977; 28: 49-55. [Google Scholar]

21. Sreedharan, S., Amith, G., Katisangla, A., Kirankumar, S. V., Praveen Kumar, K., Patil, S. J. Bioactive molecules and antimicrobial studies of Rhus semialata seeds. Res. J. Med Plants. 2020; 13(1): 10-17.

22. Prashith Kekuda, T. R., Siddiqha, A., Pushpavathi, D., Vinayaka, K. S., Raghavendra, H. L. Radical scavenging, cytotoxic and antimicrobial activity Flacourtia indica (Burm. f.) Merr. Health Sci. Res. J. 2017; 1(1): 76-82.

23. Sannigrahi, S., Mazuder, U. K., Pal, D. K., Parida, S., Jain, S. Antioxidant potential of crude extract and different fractions of Enhydra fluctuans Lour. Iran. J. of Pharm. Res. 2010; 9 (1): 75-82.

24. Osawa, T. Novel natural antioxidants for utilization in food and biological systems. In: Uritani I, Garcia VV, Mendoza E.M. (Eds) Post harvest biochemistry of plant foodmaterials in the tropics. Jap. Scien. Socie. Pres. Japan. 1994: 241-251.

25. Haleshappa, R., Patil, S. J., Usha, T., Murthy, S. M. Phytochemicals, antioxidant profile and GCMS analysis of ethanol extract of Simarouba glauca Seeds. Asian J. Biol. Life Sci. 2020; 9(3): 379-385.

26. Rajeev, R. K., Haleshappa, R., Sajeeda, N., Keshamma, E., Kaigar, C. S., Patil, S. J. Antioxidant and anticancer properties of ethanol extracts of Leucas aspera. Asian J. Bio and Life Sci. 2021; 10(1): 08-14.

27. Singh, S. V., Shrivastava, A., Jyotshna, Chaturvedi, U., Singh, S. C., Shanker, K., et al., A mechanism-based pharmacological evaluation of efficacy of Flacourtia indica in management of dyslipidemia and oxidative stress in hyperlipidemic rats. J Basic Clin Physiol Pharmacol. 2016; 27(2): 121-129. 